\title{
Quality of Life in Glaucoma
}

\author{
${ }^{1}$ Alexander Spratt,${ }^{2}$ Aachal Kotecha, ${ }^{3}$ Ananth Viswanathan \\ ${ }^{1}$ Department of Ophthalmology, The Royal Free Hospital, London \\ ${ }^{2}$ Glaucoma Research Unit, Moorfields Eye Hospital, London \\ ${ }^{3}$ Glaucoma Service, Moorfields Eye Hospital, London
}

\section{INTRODUCTION}

A sizeable and growing body of evidence clearly demonstrates that patients value their vision more highly than most ophthalmologists realise. ${ }^{1}$ Closing this gap between patients' experiences and ophthalmologists' perceptions remains an elusive but worthwhile goal; in failing to do so we risk doing less than our best for patients.

'Success' in glaucoma has always been a moving target. It has evolved from the hope that an intraocular pressure (IOP) of $21 \mathrm{mmHg}$ or less would prevent visual loss to encompass the results of a complex battery of hospital-administered tests including assessment of IOP, visual field stability, optic nerve and nerve fibre layer status.

Conspicuous by their absence are attempts to evaluate patients' ability to perform visually demanding tasks, to understand patients' satisfaction with their vision and to tackle patients' fears. The aim of this review is to remind ophthalmologists that it is these factors, and how they impact on quality of life (QOL), that patients consider most important. Redefining success as judged by these terms may be just what the patient ordered.

\section{What is 'Quality of Life'?}

Put simply, QOL is determined by an individual's own assessment of their physical, psychological and social wellbeing. The right to drive, the freedom to live independently and enjoy life all contribute to a 'good' QOL and each of these have a sight-dependent component.

It is well recognized that patients with similar disease states, including those suffering glaucomatous visual loss, are likely to rate its impact on their QOL quite differently. Perceived QOL differs between individuals, with variability based on cultural beliefs, social circumstances and personal expectations. It also varies within individuals overtime, based on life experiences and changing personal expectations. However, even with this variable personal resilience, research studies with sufficiently large sample sizes have provided useful information about the QOL impact of glaucoma.

\section{ASSESSMENT OF QOL IN GLAUCOMA}

Although researchers have a choice of techniques with which to measure QOL in glaucoma this still remains a relatively new endeavour. Only in the last decade have systematic efforts been made to understand the effect of glaucoma on patients' lives.

This young science incorporates self-reported visual ability by questionnaire, directly observed performance-based evidence and utility analyses in its forms of assessment.

\section{QUESTIONNAIRES}

Historically, health-related QOL research has been carried out using interview-administered or self-reported questionnaires to present a subjective, patient-based assessment of the impact of a disease and its treatment on their well-being. In vision research, questionnaires are used to assess patients' perceived visual functional abilities with responses often correlated to objective measures such as visual acuity and visual field to confirm a causal link and thereby 'validity'. Such results are often then used to infer that patients with reduced visual abilities have a poorer vision-related QOL.

Health questionnaires can be broadly divided into those assessing general health, those which are system specific in their questioning and those which are disease specific.

Each of these types has been used to assess QOL in patients with glaucoma.

\section{General Health-related QOL Questionnaires}

These were first developed to provide a patient-derived measure of the overall impact of sickness or surgery ${ }^{2}$ and have since been used to assess the effects of ophthalmic interventions and visual loss on patients' QOL. Part of the value of providing a generic overview of health is that it allows for comparison of data across various disease states.

The Medical Outcomes Study Short-Form Health Survey (SF36) measures patients' perceptions in 8 areas — general health, physical function, role limitations due to physical and mental 
disability, social function, vitality, mental health and bodily pain. ${ }^{3}$ Studies using the SF-36 in patients with glaucoma have found weak or absent correlations with binocular visual field $\operatorname{loss}^{4,5}$ and a mixed ability to discriminate between patients with and without glaucoma. ${ }^{5-7}$

The Collaborative Initial Glaucoma Treatment Study (CIGTS) is one of the largest randomized controlled clinical trials to have collected longitudinal data on QOL in newly diagnosed glaucoma patients. Their QOL assessment used six questionnaires to assess general health and disease-specific aspects of impairment, functional status and health perceptions. One questionnaire, the Sickness Impact Profile (SIP)—a modified general health QOL questionnaire-showed no association between reduced functional health status and newly diagnosed glaucoma. ${ }^{7}$

With such weak associations, general health questionnaires used in isolation play only a very limited role in the assessment of the QOL impact of glaucoma.

\section{Vision-specific QOL Questionnaires}

These were developed in the early 1990s with the primary goal of assessing the effect of cataract on patients' perceived visual ability. ${ }^{8}$ They assess ocular symptoms and specific difficulties with vision-dependent tasks. Questions investigating a similar theme are often grouped into 'subscales' to allow for subanalysis. Examples of such subscales include ocular pain, distance vision, driving and role limitations and reflect the origins of these questionnaires in the investigation of visual impact of cataract. Vision-specific questionnaires are more discerning for ocular disease but do not allow for comparison with differing non-ocular disease states.

The Activities of Daily Vision Scale (ADVS) was the first vision specific QOL questionnaire. ${ }^{9}$ It was designed to assess the visual ability of cataract patients and consists of 22 questions grouped into 5 subscales - near vision, distance vision, glare disability, daytime driving and night driving. Patients rate the difficulty of each visual task on a five-point scale ranging from 'no difficulty at all' to 'stopped doing because of vision'. Studies have suggested that only the near vision and night driving subscales are truly statistically independent; the other 3 subscales show intercorrelations. All subscales, however, are significantly associated with clinical measures of visual function. ${ }^{10}$ When applied to glaucoma, the ADVS was able to reliably differentiate glaucoma patients from normal controls, and poorer overall ADVS scores were shown to correlate well with the degree of field loss. ${ }^{11}$

The Visual Function Index (VF-14) was also developed to assess functional impairment in patients with cataract. Its questions were established by expert consensus to encompass a broad spectrum of vision-dependent activities including cooking, reading newsprint, seeing stairs and night driving. As with the ADVS it requires the patient to rate the difficulty of each task. ${ }^{12}$ The outcome, in the form of a single visual function score, was only moderately correlated in cataract patients with visual acuity in the better eye but was strongly correlated with self-reported overall visual trouble and overall satisfaction with vision. When used in the assessment of glaucoma the difference between the VF-14 scores of glaucoma patients and normal controls did not reach statistical significance. ${ }^{4}$ However, VF-14 scores did correlate with the extent of visual field loss, albeit to a lesser degree than that observed using the ADVS questionnaire. $^{4,11}$

The Visual Activities Questionnaire (VAQ) was developed to assess difficulty with everyday visual tasks experienced by elderly patients. It consists of 33 questions grouped into 10 subscales encompassing visual abilities that are recognized to decline with age. ${ }^{13}$ As it has a subscale specifically assessing peripheral vision it was selected for inclusion in the QOL assessments of the CIGTS which found overall VAQ scores to correlate with both visual acuity and visual field. ${ }^{7}$ The peripheral vision subscale not only correlated highly with the presence of visual field impairment but also showed correlation with the degree of severity of visual field loss in the worse eye. ${ }^{7}$

The Impact of Vision Impairment (IVI) questionnaire measures the impact of impaired vision on common daily experiences. It asks 32 questions, covering a broad range of practical and psychosocial activities within five subscales. ${ }^{14}$ Used to assess glaucoma no correlation was demonstrated between visual field loss and the overall IVI score, although a correlation was found to responses in the mobility subscale. Notably, a quarter of glaucoma patients with relatively minor binocular field loss reported a moderate to severe mobility restriction ${ }^{15}$ in keeping with previous observations of impaired mobility performance in glaucoma. ${ }^{16}$

The National Eye Institute-Visual Function Questionnaire (NEI-VFQ) was developed with the help of patient focus groups to measure the effects of a variety of ocular conditions on daily functioning and QOL. It was originally designed as a 51-point questionnaire and later redeveloped for convenience using 25 of the original questions (NEI-VFQ25) ${ }^{17}$ Both formats have been validated and widely used to assess ocular disease and, by comparison, used to authenticate the results of other questionnaires. When used to assess glaucoma, the severity of visual field loss correlated with the overall NEI-VFQ25 score and the peripheral vision and vision-specific dependency subscales of the original NEI-VFQ. ${ }^{4,18}$ Furthermore, the NEIVFQ scores of glaucoma patients were lower across most subscales, including driving and vision-specific role difficulties, poorer scores correlating with more severe visual field defects of the better eye. ${ }^{19}$ 


\section{Glaucoma Specific QOL Questionnaires}

These were developed in response to the relative weaknesses of vision-specific questionnaires. By incorporating questions specific to the visual disabilities experienced by glaucoma patients, investigators hoped to find an alternative method of determining disease severity. Most questions focus on straightforward visual ability, specific task performance and the impact of reduced visual ability on patients. There are currently five glaucoma specific questionnaires in the literature.

The Glaucoma Symptom Scale (GSS) scores ten symptoms commonly experienced by glaucoma patients on a five-point rating scale (Table 1). Questions are divided into those assessing non-visual symptoms, including stinging and foreign-body sensation, and those assessing visual symptoms which include difficulty seeing in daylight and blurry vision; it does not assess specific task performance. The GSS is able to effectively discriminate between glaucoma patients and normal controls ${ }^{20}$ but another study found no association between Esterman visual field scores and those of the GSS. ${ }^{15}$ The GSS may therefore have a niche role in measuring the symptoms of medical and surgical treatments of glaucoma, rather than providing a rounded measure of QOL.

The Viswanathan Questionnaire, as named by Iester et al, ${ }^{21}$ also consists of ten questions but asks subjects to make a binary ‘yes' or 'no' response (Table 2). ${ }^{22}$ It includes questions about bumping into things, finding dropped objects and tripping/difficulty with stairs. This questionnaire evolved from
Mills and Drance's earlier questionnaire assessing disability in patients with severe glaucoma. ${ }^{23}$ Responses correlate well with visual field mean deviation and pattern standard deviation ${ }^{21}$ and also with Esterman visual field score, ${ }^{22}$ suggesting that this questionnaire effectively targets activities specific to glaucoma. Of note, this questionnaire has also demonstrated that even patients with only mild to moderate glaucomatous visual field loss have subjective perceived visual disability. ${ }^{22}$

The Glaucoma Quality of Life (GQL-15) questionnaire asks 15 rating-scored questions to assess the degree of functional disability caused by glaucoma. The questions used were the 15 most significant predictors of visual field loss derived from an original 62 point questionnaire. ${ }^{24}$ They include six questions relating to actions demanding functional peripheral vision, six relating to dark adaptation and glare, two relating to central and near vision and one relating to outdoor mobility (Table 3). None of the original questions relating to personal care or household tasks qualified for inclusion in the final GQL-15. A significant correlation exists between overall GQL-15 scores and a number of psychophysical tests including contrast sensitivity, glare disability, dark adaptation, stereopsis and Esterman visual field score. ${ }^{24}$ The same study also found significantly greater perceived visual disability amongst glaucoma patients with mild visual field loss (defined as unilateral visual field loss of less than a hemifield) compared with control subjects, suggesting that early glaucomatous loss is readily discernable to patients. This extends upon the findings of Viswanathan and colleagues and further challenges the belief that glaucoma is an asymptomatic condition in its early stages.

Table 1: The glaucoma symptom scale (GSS) ${ }^{20}$

\begin{tabular}{|c|c|c|c|c|c|c|}
\hline & & $\begin{array}{l}\text { Yes, } \\
\text { very } \\
\text { bothersome }\end{array}$ & $\begin{array}{l}\text { Yes, } \\
\text { somewhat } \\
\text { bothersome }\end{array}$ & $\begin{array}{l}\text { Yes, } \\
\text { a little } \\
\text { bothersome }\end{array}$ & $\begin{array}{l}\text { Yes, } \\
\text { but not } \\
\text { bothersome at all }\end{array}$ & $\begin{array}{l}\text { No, } \\
\text { absent }\end{array}$ \\
\hline 1. & Burning, smarting, stinging & & & & & \\
\hline 2. & Tearing & & & & & \\
\hline 3. & Dryness & & & & & \\
\hline 4. & Itching & & & & & \\
\hline 5. & Soreness, tiredness & & & & & \\
\hline 6. & Blurry or dim vision & & & & & \\
\hline 7. & Feeling of something in the eye & & & & & \\
\hline 8. & Hard to see in daylight & & & & & \\
\hline 9. & Hard to see in dark places & & & & & \\
\hline 10. & Halos around lights & & & & & \\
\hline
\end{tabular}


Alexander Spratt et al

\begin{tabular}{l|l|l}
\hline \multicolumn{1}{c}{ Table 2: The Viswanathan questionnaire 22} & & Yes \\
\hline Please answer the questions below: & & No \\
\hline Do you ever notice that parts of your field of vision are missing? & & \\
\hline Have you noticed any deterioration in your sight over the last few years? & & \\
\hline Do you ever have trouble following a line of print or finding the next line when reading? & & \\
\hline Do you notice variation in color intensity? & & \\
\hline Do you bump into things sometimes? & & \\
\hline Do you trip on things or have difficulty with stairs? & & \\
\hline Have you had to give up activities because of your sight? & & \\
\hline Do you have difficulty finding things that you have dropped? & & \\
\hline Are you troubled by glare or dazzled on sunny days or in bright lighting? & & \\
\hline Do you have particular difficulty seeing after moving from a light to a dark room? & & \\
\hline
\end{tabular}

Table 3: The glaucoma quality of life (GQL-15) questionnaire ${ }^{24}$

\begin{tabular}{|c|c|c|c|c|c|c|}
\hline The Claucoma Quality of Life-15 quest & ionnaire & $\begin{array}{r}\mathrm{A} \\
\text { it of daily } a\end{array}$ & $\begin{array}{l}\text { NDIX } \\
\text { es with }\end{array}$ & strongest re & onship $w$ & field loss in glaucoma \\
\hline $\begin{array}{l}\text { Patient instruction: Please, circle the corre } \\
\text { difficulty, [3] for some difficulty, [4] for qui } \\
\text { than visual reasons, please cirlce [0]. } \\
\text { Does your vision give you any difficul }\end{array}$ & ty, even & $\begin{array}{l}\text { he scale } r \\
\text { ifficulty, and } \\
\text { h glasses, wi }\end{array}$ & $\begin{array}{l}\text { or from } 1 \\
\text { or severe } \\
\text { followi }\end{array}$ & $\begin{array}{l}5 \text { where [1 } \\
\text { ifficulty. If y } \\
\text { activities? }\end{array}$ & $\begin{array}{l}\text { ands for } \\
\text { lo not per }\end{array}$ & $\begin{array}{l}\text { lty, [2] for a little bit of } \\
\text { of the activities for other }\end{array}$ \\
\hline & None & A little bit & Some & Quite a lot & Severe & $\begin{array}{l}\text { Do not perform for } \\
\text { nonvisual reasons }\end{array}$ \\
\hline Reading newspapers & 1 & 2 & 3 & 4 & 5 & 0 \\
\hline Walking after dark & 1 & 2 & 3 & 4 & 5 & 0 \\
\hline Seeing at night & 1 & 2 & 3 & 4 & 5 & 0 \\
\hline Walking on uneven ground & 1 & 2 & 3 & 4 & 5 & 0 \\
\hline Adjusting to bright lights & 1 & 2 & 3 & 4 & 5 & 0 \\
\hline Adjusting to dim lights & 1 & 2 & 3 & 4 & 5 & 0 \\
\hline Going from light to dark room or vice versa & 1 & 2 & 3 & 4 & 5 & 0 \\
\hline Tripping over objects & 1 & 2 & 3 & 4 & 5 & 0 \\
\hline Seeing objects coming from the side & 1 & 2 & 3 & 4 & 5 & 0 \\
\hline Crossing the road & 1 & 2 & 3 & 4 & 5 & 0 \\
\hline Walking on steps/stairs & 1 & 2 & 3 & 4 & 5 & 0 \\
\hline Bumping into objects & 1 & 2 & 3 & 4 & 5 & 0 \\
\hline Judging distance of foot to step/curb & 1 & 2 & 3 & 4 & 5 & 0 \\
\hline Finding dropped objects & 1 & 2 & 3 & 4 & 5 & 0 \\
\hline Recognizing faces & 1 & 2 & 3 & 4 & 5 & 0 \\
\hline
\end{tabular}


The Symptom Impact Glaucoma (SIG) and Glaucoma Health Perceptions Index (GHPI) are glaucoma specific questionnaires developed by the CIGTS group with the aim of providing a more complete understanding of the overall impact of glaucoma. ${ }^{7}$ The SIG consists of 43 questions, including psychological and systemic inquiries, derived from discussions with patient focus groups and ophthalmologists. Patients were asked whether they had experienced a symptom and, if so, to what degree they felt it was attributable to glaucoma or its treatment. The CIGTS group also developed the six questions GHPI which assessed the impact of glaucoma on patients' emotional, physical, social and cognitive well-being and assessed the stress caused by having glaucoma and the level of concern felt about blindness. The questionnaires were administered to newly diagnosed glaucoma patients with varying disease severity. Correlations with visual field test scores were weak for both questionnaires but showed some improvement when compared with simulated binocular visual field test scores.

\section{Limitations of Using Questionnaires to Measure QOL}

Visual function questionnaires have been developed to measure patients' perceptions of their abilities to perform the activities of daily living. However, they are a highly subjective form of self-evaluation and draw heavily upon a patient's own perception, expectations and belief system. As such their usefulness will perhaps always be limited. A superior method of assessing the impact of glaucoma on our patients' visual abilities may be the direct observation of how well they perform visually demanding tasks.

\section{PERFORMANCE-BASED ASSESSMENT OF VISUAL FUNCTION IN GLAUCOMA}

Performance-based testing offers several distinct advantages over self-reported evaluation of visual ability. Self-reports are based on patients' understanding of what the presented task might involve, their assessment of the task's relative difficulty and their own perceptions of their ability to perform that task. Performance-based testing removes this subjectivity and simply involves observing a patient's actual ability to perform a given task.

Performance-based testing is not new to medicine; it is familiar territory in the diagnosis and monitoring of stroke, ${ }^{25}$ other neurological conditions ${ }^{26-28}$ and is used to assess other problems encountered by the elderly. ${ }^{29,30}$ It has also been used in ophthalmology to assess the effects of the ageing process on visual abilities in the elderly ${ }^{31,32}$ and in studies assessing the functional abilities of low vision patients. ${ }^{33-36}$ Studies have also looked more directly at the impact of glaucoma on mobility ${ }^{16}$ and the ability to drive ${ }^{37,38}$ but none have fully assessed a patient's ability to carry out the activities of daily living. A recent addition to ophthalmological performance-based testing is the Assessment of Function Related to Vision (AFREV) test which aims to evaluate the effect of visual impairment from any cause on patients' functional ability. ${ }^{39}$ Although the test battery is not glaucoma specific, it has been used on glaucoma patients and has shown strong correlations between overall scores and Esterman visual field scores. However, many of the items on the AFREV are functional tests of central vision and as this area is left intact until relatively late in glaucoma the use of performance-based tests concentrating on central visual abilities may not fully describe the impairments of glaucoma patients with early disease. The challenge still remains to develop a performance-based test specific to the needs of glaucoma patients.

\section{UTILITY MEASURES}

Another common criticism of the use of questionnaires to assess QOL is that although they provide a measure of an individual's general health status they fall short of describing true quality of life. ${ }^{40}$

Utility theory aims to overcome the composite approach of questionnaires, instead using preference-based choices to provide a single, patient-derived, numerical value representative of quality of life. In doing so it reveals patients' perceptions of QOL related to a disease state. This technique has also been applied to medicine as a method to ascertain the costeffectiveness of medical interventions.

Utility measures are rated on a scale of 0.0 to 1.0 , zero representing death and 1.0 representing perfect health. ${ }^{41} \mathrm{~A}$ strength of this design is that it allows for effective comparison between various health states in a way not permitted by diseasespecific measures of quality of life. An example of this is that severe angina and bilateral reduced visual acuity of 6/60 have both been associated with a utility value of 0.50 suggesting that these disparate conditions have a comparable impact on quality of life.

Utility values can also be obtained from third parties, often with interesting results. In the case of age-related macular degeneration it is known that the general public, non-ophthalmic clinicians and ophthalmologists all significantly underestimate the QOL impact of this condition when compared with the patients who suffer from the disease. ${ }^{42,43}$

Several methods of assessing utility values exist. The two most commonly used measures are the time trade-off method and the standard gamble method.

Time trade-off (TTO) utility values are determined by asking patients how many years they expect to live and how many of those remaining years of life they would be willing to trade in return for perfect vision. The proportion of their future lifeexpectancy traded is then subtracted from 1.0 to arrive at a final value. 
The Standard Gamble (SG) method presents patients with an imaginary treatment that has two possible outcomes: either perfect health (or in the case of ophthalmic disease, perfect sight in both eyes) with no side-effects for the remainder of their life in cases where the treatment works, or immediate death (gamble 1) or blindness (gamble 2) when the treatment does not work. Patients are then asked what percentage chance of death or blindness they would be prepared to risk before refusing the treatment offered. This percentage is then subtracted from 1.0 to obtain the utility value.

Utility values have been used to assess glaucoma patients. A study of 191 glaucoma patients and 46 glaucoma suspects found that only $22 \%$ of glaucoma and $11 \%$ of glaucoma suspect patients were willing to trade any life expectancy for perfect vision, giving modest average TTO utility values of 0.93 and 0.98 respectively. ${ }^{5}$ These utility values showed poor correlation with Esterman visual fields. By comparison, twelve blind patients from the same study had an average TTO utility value of 0.67 , meaning they were willing to trade a third of their remaining life expectancy for a permanent return to perfect vision. A study of 213 Chinese Singaporean glaucoma patients found that most were not willing to trade life expectancy or risk blindness for a glaucoma-free life; their mean TTO utility value was 0.88 and SG for death and blindness 0.94 and 0.95 respectively. ${ }^{44}$ By contrast, a study of 105 Indian glaucoma patients found an average TTO utility value of 0.64 unrelated to the extent of visual field loss. ${ }^{45}$ The authors suggest the marked difference in their utility value may reflect the severity of glaucoma in their patients and the differing impact of chronic disease and visual impairment in developing countries. ${ }^{45}$

\section{CONCLUSION}

Much work has been done and much more is needed to understand the impact of glaucoma on individuals and their ability to perform the activities of daily living. Only in achieving this can we hope to understand our patients, comprehend what it is they want from us and at what personal cost, and begin to calculate the true worth of our treatments to patients and society.

\section{REFERENCES}

1. Stein JD. Disparities between ophthalmologists and their patients in estimating quality of life. Curr Opin Ophthalmol 2004;15:238-43.

2. Gilson BS, Gilson JS, Bergner M, et al. The sickness impact profile. Development of an outcome measure of health care. Am J Public Health 1975;65:1304-10.

3. Ware JE, Sherbourne CD. The MOS 36-item short-form health survey (SF-36). I. Conceptual framework and item selection. Med Care 1992;30:473-83.

4. Parrish RK 2nd, Gedde SJ, Scott IU, et al. Visual function and quality of life among patients with glaucoma. Arch Ophthalmol 1997;115:1447-55.
5. Jampel HD, Schwartz A, Pollack I, et al. Glaucoma patients' assessment of their visual function and quality of life. J Glaucoma 2002;11:154-63.

6. Wilson MR, Coleman AL, Yu F, et al. Functional status and well-being in patients with glaucoma as measured by the Medical Outcomes Study Short Form-36 questionnaire. Ophthalmology 1998;105:2112-6.

7. Janz NK, Wren PA, Lichter PR, et al. Quality of life in newly diagnosed glaucoma patients: The Collaborative Initial Glaucoma Treatment Study. Ophthalmology 2001;108:887-97; discussion 898.

8. Mangione CM, Phillips RS, Seddon JM, et al. Development of the 'Activities of Daily Vision Scale'. A measure of visual functional status. Med Care 1992;30:1111-26.

9. Mangione CM, Phillips RS, Sneddon JM. Development of the "activities of daily vision scale": a measure of visual functional status. Med Care 1992;30:1111-26.

10. Valbuena M, Bandeen-Roche K, Rubin GS, et al. Self-reported assessment of visual function in a population-based study: the SEE project. Salisbury Eye Evaluation. Invest Ophthalmol Vis Sci 1999;40:280-8.

11. Sherwood MB, Garcia-Siekavizza A, Meltzer MI, et al. Glaucoma's impact on quality of life and its relation to clinical indicators: a pilot study. Ophthalmology 1998;105:561-6.

12. Steinberg EP, Tielsch JM, Schein OD, et al. The VF-14: an index of functional impairment in patients with cataract. Arch Ophthalmol 1994;112:630-8.

13. Sloane ME, Ball K, Owsley C, et al. The visual activities questionnaire: developing an instrument for assessing problems in everyday visual tasks. OSA Tech Dig Noninvasive Asses Vis Sys (Washington, DC:Optical Society of America) 1992;1:269.

14. Weih LM, Hassell JB, Keeffe J. Assessment of the impact of vision impairment. Invest Ophthalmol Vis Sci 2002;43:927-35.

15. Noe G, Ferraro J, Lamoureux E, et al. Associations between glaucomatous visual field loss and participation in activities of daily living. Clin Experiment Ophthalmol 2003;31:482-6.

16. Turano KA, Rubin GS, Quigley HA. Mobility performance in glaucoma. Invest Ophthalmol Vis Sci 1999;40:2803-9.

17. Mangione CM, Lee PP, Gutierrez PR, et al. Development of the 25-item National Eye Institute Visual Function Questionnaire. Arch Ophthalmol 2001;119:1050-8.

18. Jampel HD, Friedman DS, Quigley H, et al. Correlation of the binocular visual field with patient assessment of vision. Invest Ophthalmol Vis Sci 2002;43:1059-67.

19. Gutierrez P, Wilson MR, Johnson C, et al. Influence of glaucomatous visual field loss on health-related quality of life. Arch Ophthalmol 1997;115:777-84.

20. Lee BL, Gutierrez P, Gordon M, et al. The Glaucoma Symptom Scale. A brief index of glaucoma-specific symptoms. Arch Ophthalmol 1998;116:861-6.

21. Iester M, Zingirian M. Quality of life in patients with early, moderate and advanced glaucoma. Eye 2002;16:44-9.

22. Viswanathan AC, McNaught AI, Poinoosawmy D, et al. Severity and stability of glaucoma: patient perception compared with objective measurement. Arch Ophthalmol 1999;117:450-4. 
23. Mills RP, Drance SM. Esterman disability rating in severe glaucoma. Ophthalmology 1986;93:371-8.

24. Nelson P, Aspinall P, Papasouliotis O, et al. Quality of life in glaucoma and its relationship with visual function. J Glaucoma 2003;12:139-50.

25. Chong DK. Measurement of instrumental activities of daily living in stroke. Stroke 1995;26:1119-22.

26. Shulman LM, Pretzer-Aboff I, Anderson KE, et al. Subjective report versus objective measurement of activities of daily living in Parkinson's disease. Mov Disord 2006;21:794-9.

27. Louis ED, Tang MX, Schupf N, et al. Functional correlates and prevalence of mild parkinsonian signs in a community population of older people. Arch Neurol 2005;62:297-302.

28. Loewenstein DA, Amigo E, Duara R, et al. A new scale for the assessment of functional status in Alzheimer's disease and related disorders. J Gerontol 1989;44:114-21.

29. Seeman TE, Charpentier PA, Berkman LF, et al. Predicting changes in physical performance in a high-functioning elderly cohort: MacArthur studies of successful aging. J Gerontol 1994;49:97-108.

30. Jerome GJ, Glass TA, Mielke M, et al. Physical activity participation by presence and type of functional deficits in older women: The Women's Health and Aging Studies. J Gerontol A Biol Sci Med Sci 2006;61:1171-6.

31. Owsley C, McGwin G, Sloane ME, et al. Timed instrumental activities of daily living tasks: relationship to visual function in older adults. Optom Vis Sci 2001;78:350-9.

32. Owsley C, Sloane M, McGwin G, et al. Timed instrumental activities of daily living tasks: relationship to cognitive function and everyday performance assessments in older adults. Gerontology 2002;48:254-65.

33. Ebert EM, Fine AM, Markowitz J, et al. Functional vision in patients with neovascular maculopathy and poor visual acuity. Arch Ophthalmol 1986;104:1009-12.

34. Alexander MF, Maguire MG, Lietman TM, et al. Assessment of visual function in patients with age-related macular degeneration and low visual acuity. Arch Ophthalmol 1988;106:1543-7.

35. Szlyk JP, Seiple W, Fishman GA, et al. Perceived and actual performance of daily tasks: relationship to visual function tests in individuals with retinitis pigmentosa. Ophthalmology 2001;108:65-75.

36. Szlyk JP, Fishman GA, Grover S, et al. Difficulty in performing everyday activities in patients with juvenile macular dystrophies: comparison with patients with retinitis pigmentosa. Br J Ophthalmol 1998;82:1372-6.

37. McGwin G, Mays A, Joiner W, et al. Is glaucoma associated with motor vehicle collision involvement and driving avoidance? Invest Ophthalmol Vis Sci 2004;45:3934-9.
38. Adler G, Bauer MJ, Rottunda S, et al. Driving habits and patterns in older men with glaucoma. Soc Work Health Care 2005;40:7587.

39. Altangerel U, Spaeth GL, Steinmann WC. Assessment of function related to vision (AFREV). Ophthalmic Epidemiol 2006;13:6780 .

40. Bradley C. Importance of differentiating health status from quality of life. Lancet, 2001;357:7-8.

41. Redelmeier DA, Detsky AS. A clinician's guide to utility measurement. Prim Care 1995;22:271-80.

42. Brown GC, Brown MM, Sharma S. Difference between ophthalmologists' and patients' perceptions of quality of life associated with age-related macular degeneration. Can J Ophthalmol 2000;35:127-33.

43. Stein JD, Brown MM, Brown GC, et al. Quality of life with macular degeneration: perceptions of patients, clinicians, and community members. Br J Ophthalmol 2003;87:8-12.

44. Saw SM, Gazzard G, Eong KG, et al. Utility values in Singapore Chinese adults with primary open-angle and primary angleclosure glaucoma. J Glaucoma 2005;14:455-62.

45. Gupta V, Srinivasan G, Mei SS, et al. Utility values among glaucoma patients: an impact on the quality of life. $\mathrm{Br} \mathrm{J}$ Ophthalmol 2005;89:1241-4.

Adapted from 'Shaarawy T, Sherwood MB, Hitchings RA, Crowston JG (Eds): Glaucoma. London: Saunders, 2009 (forthcoming).

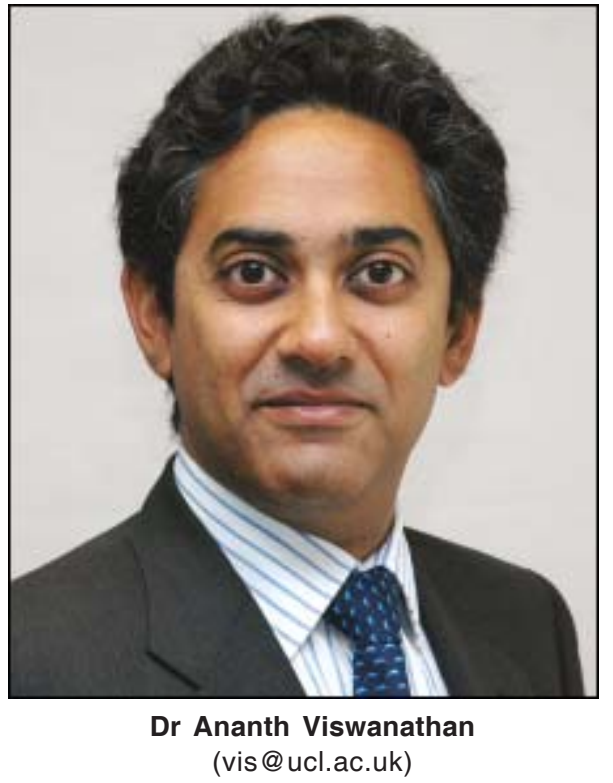

